\title{
Pre-procedural abnormal function of von Willebrand Factor is predictive of bleeding after surgical but not transcatheter aortic valve replacement
}

\author{
Kajetan Grodecki ${ }^{1}$ (1) Karol Zbroński ${ }^{1}$ [D Elżbieta Przybyszewska-Kazulak ${ }^{2}$ Anna Olasińska-Wiśniewska ${ }^{3}$. \\ Radosław Wilimski ${ }^{4}$ - Bartosz Rymuza ${ }^{1}$. Piotr Scisło ${ }^{1}$. Paweł Czub ${ }^{4}$. Dominika Koper ${ }^{1}$. Janusz Kochman ${ }^{1}$. \\ Katarzyna Pawlak ${ }^{2} \cdot$ Olga Ciepiela $^{2} \cdot$ Marek Grygier $^{3} \cdot$ Marek Jemielity $^{5} \cdot$ Maciej Lesiak $^{3} \cdot$ Krzysztof J. Filipiak $^{1}$. \\ Grzegorz Opolski ${ }^{1} \cdot$ Zenon Huczek $^{1}$
}

Published online: 29 July 2019

(c) The Author(s) 2019

\begin{abstract}
Both transcatheter aortic valve implantation (TAVI) and surgical aortic valve replacement (SAVR) have been proven to effectively correct von Willebrand Factor (vWF) pathologies, however there is limited data simultaneously comparing outcomes of both approaches. We prospectively enrolled patients with severe aortic stenosis referred for TAVI $(n=52)$ or SAVR $(n=48)$. In each case, $\mathrm{vWF}$ antigen (vWF:Ag), $\mathrm{vWF}$ activity (vWF:Ac) and activity-to-antigen (vWF:Ac/Ag) ratio were assessed at baseline, $24 \mathrm{~h}$ and $72 \mathrm{~h}$ after procedure. VWF abnormalities were defined as reduced vWF:Ac/Ag ratio $(<0.8)$. Bleeding events in both arms were classified according to Valve Academic Research Consortium (VARC-2) definitions. Overall, there was no difference between patients referred for TAVI and SAVR in vWF:Ac (1.62 \pm 0.52 vs $1.71 \pm 0.64 ; \mathrm{p}=0.593)$, vWF:Ag $(1.99 \pm 0.81$ vs $2.04 \pm 0.81 ; \mathrm{p}=0.942)$ or vWF:Ac/Ag ratio ( $0.84 \pm 0.16$ vs $0.85 \pm 0.12 ; \mathrm{p}=0.950)$. Pathological vWF:Ac/ Ag ratio was found in $20(38 \%)$ TAVI and $15(31 \%)$ SAVR patients $(\mathrm{p}=0.407)$. Normalization of $\mathrm{vWF}$ :Ac/Ag ratio at day 3 after procedure was achieved in $19(95 \%)$ TAVI and $13(87 \%)$ SAVR patients $(\mathrm{p}=0.439)$. Similar prevalence of major or life-threatening bleedings (MLTB) after TAVI and SAVR in entire groups was observed (19\% vs. 23\%, $\mathrm{p}=0.652)$. VWF abnormalities were associated with higher incidence of MLTB in SAVR (53\% vs 9\%, p < 0.001), but not TAVI (15\% vs. $22 \%, \mathrm{p}=0.132$ ). Accordingly, in receiver-operating characteristic curve analysis vWF:Ac/Ag ratio $<0.8$ showed significant sensitivity and specificity for predicting MLTB in SAVR group (AUC 0.735, 95\% CI 0.538-0.931, p=0.019). We proved that abnormal function of vWF is corrected successfully after both TAVI and SAVR, but vWF abnormalities are predictive of MLTB only in surgical patients.
\end{abstract}

Keywords von Willebrand Factor · Aortic stenosis · Transcatheter aortic valve implantation · Surgical aortic valve implantation $\cdot$ Bleeding complications

\section{Highlights}

Electronic supplementary material The online version of this article (https://doi.org/10.1007/s11239-019-01917-7) contains supplementary material, which is available to authorized users.

Karol Zbroński

karol.zbronski@gmail.com

$1 \quad 1$ st Department of Cardiology, Medical University of Warsaw, 1a Banacha, 02-097 Warsaw, Poland

2 Department of Laboratory Diagnostics, Medical University of Warsaw, Warsaw, Poland
- Von Willebrand Factor abnormalities are associated with severity of aortic stenosis.

3 1st Department of Cardiology, Poznan University of Medical Sciences, Poznan, Poland

4 Department of Cardiac Surgery, Medical University of Warsaw, Warsaw, Poland

5 Department of Cardiac Surgery and Transplantology, Poznan University of Medical Sciences, Poznan, Poland 
- Both TAVI and SAVR are effective treatment for vWF abnormalities.

- Baseline vWF abnormalities predict MLTB only in surgical patients.

- Von Willebrand Factor studies should be continued to improve stratification of surgical patients at risk of postoperative bleeding.

\section{Introduction}

Aortic stenosis (AS) leads inevitably to structural and functional changes in heart muscle, but affects also the blood components. The high-shear hemodynamics of stenotic aortic valve disrupts erythrocyte membranes and decreases platelet function [1]. Moreover, a large multimeric molecule of von Willebrand Factor (vWF) has been shown to undergo conformational changes as the high-velocity jet passes through the narrowed orifice [2].

VWF is the protein that plays key-role in primary hemostasis by mediating adhesion of platelets to the sites of vascular damage and shows high pro-haemostatic properties as high-molecular weight (HMW) multimer [3]. In the form of globularly shaped HMW multimers, vWF remains sensitive to shear stress, which leads to its unfolding and elongation into long-chain molecule [4]. Mechanism of conformational changes enhances functional properties of macromolecule, but is associated with exposure of binding sites for metalloprotease ADAMTS-13 that cleaves HMW multimers into smaller and less active molecules [5]. While enzymatic proteolysis counterregulates prothrombotic function of unfolded vWF strings, increased loss of HMW vWF multimers in AS leads to acquired von Willebrand syndrome (avWS) [6].

Initially linked with gastrointestinal bleeding from angiodysplasia (Heyde syndrome), vWF abnormalities are likely to underlie wider range of bleeding disorders accompanying AS. Previous studies showed that significant reduction of HMW vWF multimers is present in $20 \%$ to $70 \%$ patients with moderate to severe AS and gastrointestinal bleeding in the setting of $\mathrm{vWF}$ deficiency has been reported in up to $20 \%[7,8]$. Both transcatheter aortic valve implantation (TAVI) and surgical aortic valve replacement (SAVR) have been proven to effectively correct $v W F$ pathologies [9-12].

Additionally, vWF emerged recently as novel biomarker useful in management of patients with valvular heart diseases [13]. However, most of the studies focus on transcatheter therapies and little present-day data is available on this topic in the context of SAVR. We therefore sought to compare effect of surgical and transcatheter approaches in treatment of vWF abnormalities. Furthermore, we evaluated the usefulness of a novel latex-based immunoturbidimetric assay for detection of vWF activity to predict bleeding complications following TAVI and SAVR.

\section{Materials and methods}

\section{Study design and population}

Patients with severe symptomatic aortic stenosis who were referred for TAVI or SAVR at two participating centers (First Department of Cardiology, Medical University of Warsaw, Warsaw, Poland and First Department of Cardiology, University of Medical Sciences, Poznan, Poland) were prospectively enrolled in the study between April 2015 and January 2017.

Severe aortic stenosis was defined as aortic valve area $<1.0 \mathrm{~cm}^{2}$; or indexed valve area $<0.6 \mathrm{~cm}^{2} / \mathrm{m}^{2}$; or mean gradient $>40 \mathrm{mmHg}$; or maximum jet velocity $>4.0 \mathrm{~m} / \mathrm{s}$; or velocity ratio $<0.25$ [14].

The decision on patient qualification for TAVI or SAVR was made by the local Heart Team after careful evaluation of each case.

In TAVI: mechanically-, and self-expandable aortic valve prostheses of the second generation were used, transfemoral access with two ProGlides (Abbott Vascular, Abbott Park, Illinois, USA) for vascular closure was applied in all cases, procedures were performed in hybrid operating rooms under general anesthesia or local anesthesia with conscious sedation. Transcathether aortic valvein-valve implantation was excluded from the study.

In SAVR: stented and stentless aortic valve bioprostheses were used and minimally invasive aortic valve replacement approach was applied in all cases. Exclusion criteria included procedures such as coronary artery bypass grafting, mitral or tricuspid valve surgery, or aortic surgery combined with SAVR or application of mechanical aortic valve prosthesis.

Informed consent was obtained from all participating patients and local ethics committee granted permission for the study.

\section{Periprocedural antithrombotic regimens}

\section{TAVI}

Regarding periprocedural pharmacological treatment, patients taking no anticoagulation, where given loading doses of $300 \mathrm{mg}$ of aspirin and clopidogrel within $24 \mathrm{~h}$ before TAVI, and then continued with $75 \mathrm{mg}$ daily after the procedure.

Oral antiplatelet drugs were continued throughout the hospitalization, unless major bleeding occurred. Patients on chronic oral anticoagulant (OAC) treatment, where switched to low-molecular weight heparin (LMWH) at least $48 \mathrm{~h}$ before the start of the procedure. After TAVI 
they were treated with double therapy (either aspirin + OAC in patients without recent stent implantation or clopidogrel + OAC in patients with recent PCI).

During the procedure, unfractionated heparin (UFH) was administered to maintain an activated clotting time $($ ACT $)>300 \mathrm{~s}$ with subsequent reversal using protamine sulfate ( $1 \mathrm{~g} / 100$ units of heparin given).

\section{SAVR}

Patients on oral anticoagulation before surgery were switched to low-molecular weight heparin (LMWH) at least $48 \mathrm{~h}$ before SAVR.

During the procedure, UFH was administered prior to cardiopulmonary bypass (CPB) initiation to maintain an activated clotting time ACT $>400 \mathrm{~s}$ with subsequent reversal using protamine sulfate following weaning from $\mathrm{CPB}$ ( $1 \mathrm{~g} / 100$ units of heparin given).

In patients with aortic bioprosthetic valves who were in sinus rhythm after the operation and had no other indication for oral anticoagulation, LMWH was administered during hospital stay and aspirin $75-100 \mathrm{mg}$ /day was started on the first postoperative day and continued for 3 months. In patient with aortic bioprosthetic valve and indication for oral anticoagulation (most commonly atrial fibrillation) LMWH was continued until anticoagulation with a vitamin $\mathrm{K}$ antagonist (VKA) achieved an international normalized ration (INR) of 2.5 .

\section{Blood sampling and laboratory assays}

For all the study participants, venous peripheral blood samples were collected at three time-points: day before procedure, as well as on the first and third day after procedure. Blood samples were taken into standardized blood collection tubes containing $3.2 \%$ trisodium citrate in the room temperature and were centrifuged within $30 \mathrm{~min}$ accordingly to manufacturer's instruction $(15 \mathrm{~min}$ at $1500 \times \mathrm{g}$ ). Obtained plasma was subsequently frozen at $-80{ }^{\circ} \mathrm{C}$ and stored for no longer than 6 months.

von Willebrand Factor was characterized with: (1) vWF activity (vWF:Ac; INNOVANCE® VWF Ac); (2) vWF antigen (vWF:Ag; VWF Ag®); and activity-to-antigen (WF:Ac/vWF:Ag) ratio. Standard human plasma was used for calibration (all Siemens Healthcare Diagnostics, Eschborn, Germany). Measurements were performed within the routine laboratory analysis using Siemens Behring Coagulation System XP®.

\section{Endpoint definitions}

VWF abnormalities were defined as reduced vWF activity ( $<0.46$ or $<0.61 \mathrm{IU} / \mathrm{mL}$ depending on blood type) and/or reduced vWF activity-to-antigen ratio $(<0.8)$ [15]. Possible avWS was defined as the presence of the history of bleeding symptoms plus vWF abnormalities. Clinically suspected Heyde's syndrome was defined as the presence of severe aortic stenosis alongside a history of gastrointestinal angiodysplasia and gastrointestinal bleeding documented by endoscopy [11].

To evaluate bleeding complications Valve Academic Research Consortium-2 (VARC-2) definitions were applied. Bleeding events were classified as: life-threatening, major and minor [16].

\section{Sample size calculation}

The standard deviation (SD) and mean difference between the two treatment arms were estimated based on previous studies utilizing functional $\mathrm{vWF}$ assays in patients treated with TAVI and SAVR $[10,11]$. The required sample size was calculated by a two-sided $t$ test at a significance level of 0.05 with the following assumptions: (1) SD in each group \pm 0.2 ; (2) mean difference between the groups $=0.12$; (3) nominal test power $=0.8$. Based on this sample size estimation, a total of 90 patients (45 per group) should be enrolled in the trial.

\section{Statistical analysis}

Continuous variables are expressed as the mean \pm standard deviation were compared with Student's $t$ test, Mann-Whitney $\mathrm{U}$ test or Wilcoxon signed-rank test as appropriate. $\chi^{2}$ or Fisher's exact tests were used for comparison of categorical variables expressed as counts and percentages. The correlation between two continuous variables was measured with the bivariate Pearson correlation. In order to assess discrimination ability of $\mathrm{vWF}$ parameters in terms of predicting major and life-threatening bleeding, receiver-operating characteristic (ROC) analysis with an area under the curve (AUC [c-statistic]) was performed. All probability values reported are two-sided and a value $<0.05$ was considered to be significant. All data were processed using SPSS software, version 23 (IBM SPSS Statistics, New York, US).

\section{Results}

\section{Patients and baseline characteristics}

The study population included 52 patients treated with TAVI and 48 patients treated with SAVR. At baseline, vWF abnormalities were found in 20 (38\%) TAVI and 15 (31\%) SAVR patients, $(\mathrm{p}=0.407)$. Possible avWS was diagnosed in $3(15 \%)$ transcatheter and $3(20 \%)$ surgical patients 
Table 1 Demographics, comorbidities, and echocardiographic data of cohorts with and without von Willebrand Factor abnormalities

\begin{tabular}{|c|c|c|c|c|c|c|}
\hline & \multicolumn{3}{|l|}{ TAVI $(\mathrm{n}=52)$} & \multicolumn{3}{|l|}{ SAVR (n=48) } \\
\hline & $\begin{array}{l}\text { vWF abnormali- } \\
\text { ties }(\mathrm{n}=20)\end{array}$ & $\begin{array}{l}\text { no vWF abnormali- } \\
\text { ties }(\mathrm{n}=32)\end{array}$ & $\mathrm{p}$ value & $\begin{array}{l}\text { vWF abnormali- } \\
\text { ties }(n=15)\end{array}$ & $\begin{array}{l}\text { no vWF abnormali- } \\
\text { ties }(\mathrm{n}=33)\end{array}$ & $\mathrm{p}$ value \\
\hline \multicolumn{7}{|l|}{ Demographic data } \\
\hline Mean age (years) & $77.8 \pm 5.1$ & $77.7 \pm 6.7$ & 0.528 & $63.4 \pm 9.4$ & $66.1 \pm 11.5$ & 0.261 \\
\hline Male sex & $12(60)$ & $17(53)$ & 0.776 & $10(67)$ & $21(64)$ & 1.000 \\
\hline Logistic EuroSCORE (\%) & $20.7 \pm 13.6$ & $18.67 \pm 12.36$ & 0.792 & $5.69 \pm 6.11$ & $4.54 \pm 4.28$ & 0.252 \\
\hline STS-PROM (\%) & $4.94 \pm 2.84$ & $4.92 \pm 3.36$ & 0.735 & $1.04 \pm 0.73$ & $1.48 \pm 1.24$ & 0.459 \\
\hline Diabetes mellitus & $9(45)$ & $15(47)$ & 1.000 & $3(20)$ & $10(30)$ & 0.727 \\
\hline Arterial hypertension & $15(75)$ & $24(75)$ & 1.000 & $9(60)$ & $21(64)$ & 1.000 \\
\hline Dyslipidaemia & $15(75)$ & $26(81)$ & 0.730 & $11(73)$ & $20(61)$ & 0.521 \\
\hline COPD & $4(20)$ & $6(19)$ & 1.000 & $0(0)$ & $4(12)$ & 0.294 \\
\hline Atrial fibrillation & $9(45)$ & $9(28)$ & 0.244 & $2(13)$ & $9(27)$ & 0.462 \\
\hline CKD & $8(40)$ & $19(59)$ & 0.255 & $3(20)$ & $10(30)$ & 0.727 \\
\hline History of stroke/TIA & $1(5)$ & $3(9)$ & 1.000 & $2(13)$ & $0(0)$ & 0.093 \\
\hline CAD & $10(50)$ & $16(50)$ & 1.000 & $5(33)$ & $12(36)$ & 1.000 \\
\hline History of any bleeding & $3(15)$ & $7(22)$ & 0.540 & $3(20)$ & $6(18)$ & 0.881 \\
\hline History of GI bleeding & $2(10)$ & $3(9)$ & 0.940 & $2(13)$ & $3(9)$ & 0.655 \\
\hline \multicolumn{7}{|l|}{ Antithrombotic treatment } \\
\hline \multicolumn{7}{|l|}{ Antiplatelets } \\
\hline SAPT & $8(40)$ & $15(47)$ & 0.776 & $8(53)$ & $10(30)$ & 0.198 \\
\hline DAPT & $4(20)$ & $7(22)$ & 1.000 & $1(7)$ & $3(9)$ & 1.000 \\
\hline Anticoagulants & $9(45)$ & $9(28)$ & 0.244 & $1(7)$ & $10(30)$ & 0.136 \\
\hline \multicolumn{7}{|l|}{ Preprocedural TTE } \\
\hline $\operatorname{LVEF}(\%)$ & $47.3 \pm 15.3$ & $53.8 \pm 14.6$ & 0.416 & $61.2 \pm 8.6$ & $55.9 \pm 10.9$ & 0.111 \\
\hline $\operatorname{AVA}\left(\mathrm{cm}^{2}\right)$ & $0.61 \pm 0.13$ & $0.76 \pm 0.19$ & 0.012 & $0.69 \pm 0.17$ & $0.79 \pm 0.24$ & 0.043 \\
\hline $\operatorname{Vmax}(\mathrm{m} / \mathrm{s})$ & $4.4 \pm 0.4$ & $4.2 \pm 0.9$ & 0.181 & $4.4 \pm 0.7$ & $4.4 \pm 0.9$ & 0.772 \\
\hline Mean PG (mmHg) & $52.3 \pm 14.1$ & $41.7 \pm 18.5$ & 0.062 & $51.2 \pm 14.9$ & $49.4 \pm 19.3$ & 0.306 \\
\hline Max PG (mmHg) & $84.0 \pm 19.8$ & $74.5 \pm 32.0$ & 0.284 & $83.8 \pm 22.0$ & $82.4 \pm 30.4$ & 0.456 \\
\hline \multicolumn{7}{|l|}{ Predischarge TTE } \\
\hline $\operatorname{LVEF}(\%)$ & $53.6 \pm 11.2$ & $54.9 \pm 12.0$ & 0.582 & $61.0 \pm 7.8$ & $55.8 \pm 10.8$ & 0.089 \\
\hline $\operatorname{AVA}\left(\mathrm{cm}^{2}\right)$ & $1.72 \pm 0.56$ & $1.84 \pm 0.61$ & 0.305 & $1.92 \pm 0.28$ & $2.04 \pm 0.39$ & 0.620 \\
\hline $\operatorname{Vmax}(\mathrm{m} / \mathrm{s})$ & $1.8 \pm 0.6$ & $1.9 \pm 0.4$ & 0.183 & $2.4 \pm 0.4$ & $2.4 \pm 0.4$ & 0.650 \\
\hline Mean PG (mmHg) & $9.1 \pm 4.2$ & $8.5 \pm 3.9$ & 0.409 & $16.4 \pm 7.7$ & $14.4 \pm 6.0$ & 0.350 \\
\hline Max PG (mmHg) & $16.6 \pm 6.9$ & $16.7 \pm 6.6$ & 0.951 & $29.9 \pm 12.8$ & $26.4 \pm 8.9$ & 0.476 \\
\hline $\mathrm{AR}$ of at least moderate degree & $1(5)$ & $2(7)$ & 1.000 & $0(0)$ & $0(0)$ & $\mathrm{n} / \mathrm{a}$ \\
\hline
\end{tabular}

Values are $\mathrm{n}(\%)$ or mean $\pm \mathrm{SD}$

$A R$ aortic regurgitation, $A V A$ aortic valve area, $A V A i$ aortic valve area indexed for body surface, $C A D$ coronary artery disease, $C K D$ chronic kidney disease, $C O P D$ chronic obstructive pulmonary disease, $D A P T$ dual antiplatelet therapy, $L V E F$ left ventricular ejection fraction, $P G$ pressure gradient, SAPT single antiplatelet therapy, TTE transthoracic echo, TIA transient ischemic attack, Vmax peak velocity

$(\mathrm{p}=0.698)$. One surgical patient had clinically suspected Heyde's syndrome.

No differences in demographic data and comorbidities were found between patients with and without vWF abnormalities neither in TAVI nor SAVR group (detailed data is presented in Table 1). Subjects with vWF abnormalities had similar rates of preoperative bleedings compared to patients without such abnormalities in both: TAVI ( $15 \%$ vs $22 \%$, $\mathrm{p}=0.540)$ and SAVR $(20 \%$ vs $18 \%, \mathrm{p}=0.881)$ populations.
Baseline echocardiographic examination did not show any significant disparities between patients with and without vWF abnormalities, except for the values of aortic valve area in transcatheter $(0.61 \pm 0.13$ vs $0.76 \pm 0.19, \mathrm{p}=0.012)$, as well as surgical $(0.69 \pm 0.17$ vs $0.79 \pm 0.24, \mathrm{p}=0.043)$ cohort.

In TAVI cohort: 43 patients received a self-expandable CoreValve Evolut R bioprosthesis, and 9 patients received a mechanically expandable Boston Scientific Lotus Valve. 
(A)

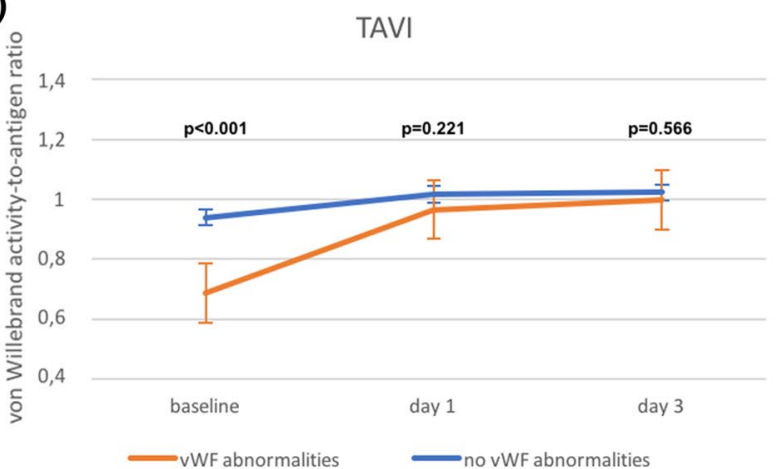

(C)

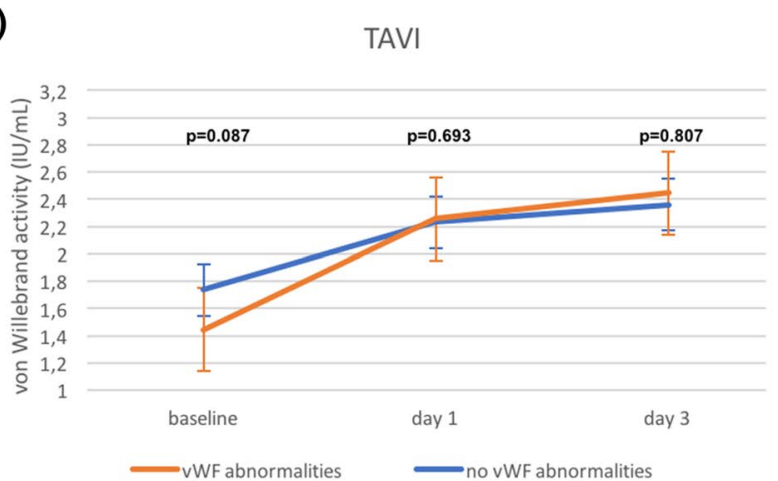

(E)

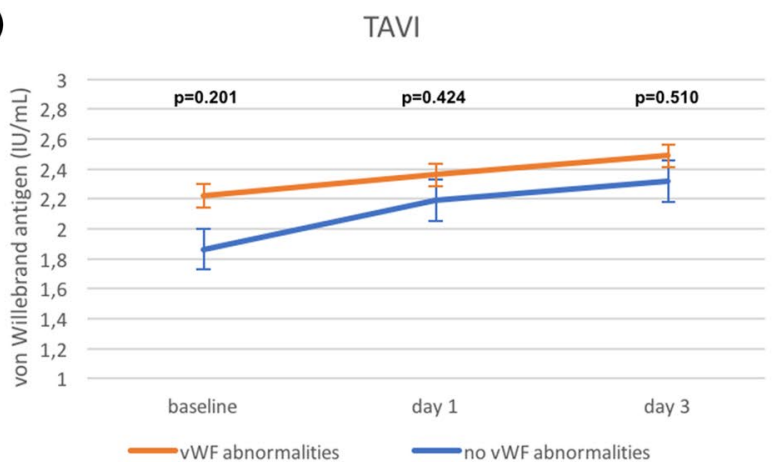

Fig. 1 Comparison of von Willebrand Factor parameters according to the treatment strategy: a von Willebrand activity-to-antigen ratio in TAVI patients; $\mathbf{b}$ von Willebrand activity-to-antigen ratio in SAVR

In SAVR cohort: 40 patients received a stented bioprostheses (30 Labcor Dokimos Plus, 4 St Jude Medical Epic, 6 Edwards Magna Ease 3000) and 8 patients received stentless Sorin Freedom Solo bioprostheses.

\section{Baseline vWF parameters}

Overall, there was no difference between patients referred for TAVI and SAVR in vWF:Ac $(1.62 \pm 0.52$ vs $1.71 \pm 0.64$; $\mathrm{p}=0.593)$, vWF:Ag $(1.99 \pm 0.81$ vs $2.04 \pm 0.81 ; \mathrm{p}=0.942)$ or vWF:Ac/Ag ratio $(0.84 \pm 0.16$ vs $0.85 \pm 0.12 ; \mathrm{p}=0.950)$.

In transcatheter as well surgical cohorts, the vWF:Ac/vWF:Ag ratio was lower in patients with vWF

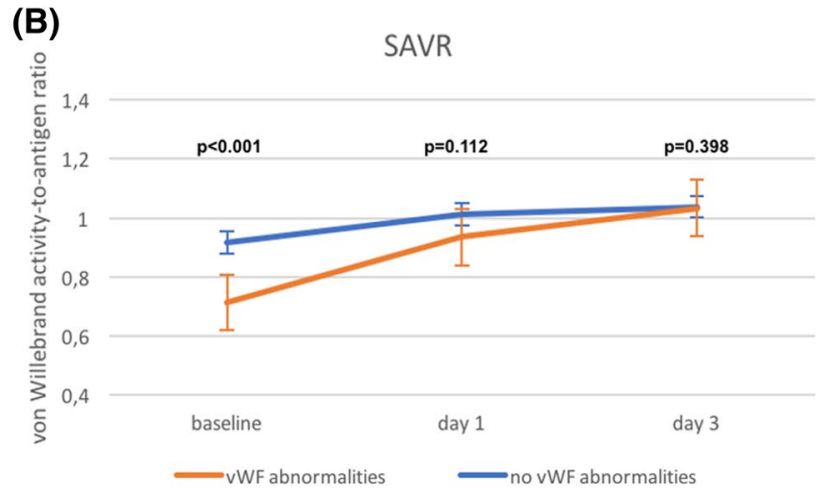

(D)

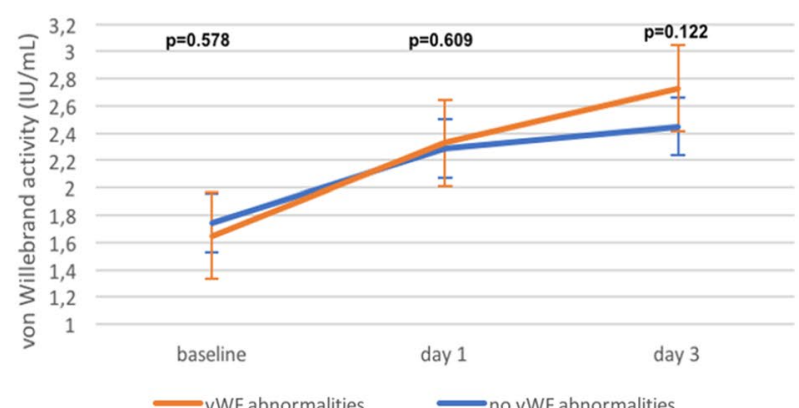

(F)

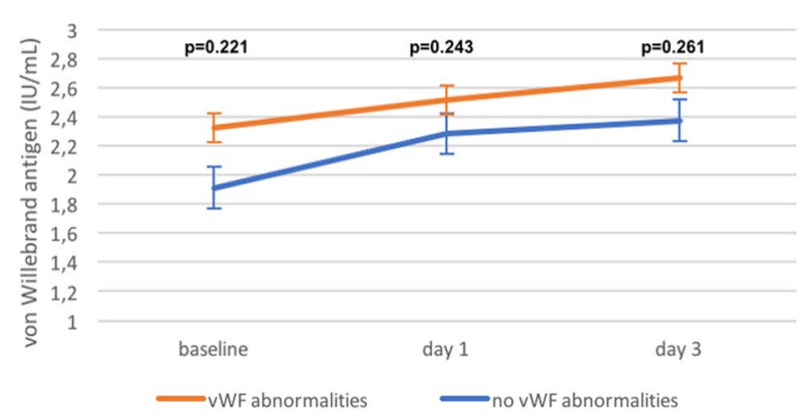

patients; $\mathbf{c}$ von Willebrand activity in TAVI patients; d von Willebrand activity in SAVR patients; $\mathbf{e}$ von Willebrand antigen in TAVI patients; $\mathbf{f}$ von Willebrand antigen in SAVR patients

abnormalities compared to patients without vWF abnromalities $(0.68 \pm 0.10$ vs $0.94 \pm 0.10, \mathrm{p}<0.001$ for TAVI; $0.71 \pm 0.05$ vs $0.92 \pm 0.10, p<0.001$ for SAVR; Fig. $1 \mathrm{a}, \mathrm{b}$ ).

In TAVI population no differences between patients with and without vWF abnormalities were found neither in mean values of vWF:Ac $(1.44 \pm 0.37$ vs $1.74 \pm 0.58$, $\mathrm{p}=0.087$; Fig. $1 \mathrm{c})$ nor mean vWF:Ag $(2.21 \pm 1.01 \mathrm{vs}$ $1.86 \pm 0.63, p=0.201 ;$ Fig. 1 e). Similar results were noted for SAVR patients with and without vWF abnormalities, in whom both vWF:Ac $(1.64 \pm 0.68$ vs $1.74 \pm 0.63, p=0.578$; Fig. 1d) and vWF:Ag $(2.32 \pm 0.96$ vs $1.91 \pm 0.71$, $\mathrm{p}=0.221$; Fig. 1f) were not significantly different. 
Bivariate Pearson correlation was performed for baseline markers of vWF function (vWF:Ac, vWF:Ag and WF:Ac/vWF:Ag ratio) with different markers of aorticvalve-stenosis severity (aortic valve area, peak velocity, mean and max pressure gradients). Mean pressure gradient showed significant negative correlation with both vWF:Ac $(r=-0.226, p=0.024$; Supplementary Fig. 1a) and vWF:Ac/vWF:Ag ratio $(r=-0.240, p=0.016$; Supplementary Fig. 1b). Moreover, peak velocity negatively correlated with vWF:Ac $(r=-0.216, p=0.031$ Supplementary Fig. 1c).

\section{Postprocedural evolution of vWF parameters}

Normalization of vWF:Ac/Ag ratio at day 3 after the procedure was achieved in 19 (95\%) TAVI and 13 (87\%) SAVR patients $(\mathrm{p}=0.439)$. Disparities between patients with and without vWF abnormalities observed in baseline vWF parameters were resolved from the first post-interventional day. In TAVI patients with baseline vWF abnormalities, vWF:Ac/Ag ratio increased to $0.96 \pm 0.11$, while in group without abnormalities increase to $1.01 \pm 0.12$ was noted on the first day ( $p=0.221$; Fig. 1a). On the third day, vWF:Ac/ Ag ratio values were: $0.99 \pm 0.14$ and $1.02 \pm 0.08$, respectively $(\mathrm{p}=0.566)$. Similarly, in surgical patients with baseline vWF abnormalities, vWF:Ac/Ag ratio increased to $0.94 \pm 0.15$ and in subjects without $\mathrm{vWF}$ abnormalities increase to $1.01 \pm 0.12$ was observed on the first postoperative day ( $p=0.112$; Fig. $1 b)$. In SAVR group, on the third day, vWF:Ac/Ag ratio was $1.03 \pm 0.15$ and $1.04 \pm 0.09$, respectively $(\mathrm{p}=0.398)$. Evolution of remaining parameters in transcatheter and surgical groups is presented in Fig. 1c-e.

No differences in relative increase of vWF:Ac/Ag ratio were found on the first post-interventional day between TAVI and SAVR neither in patients with $(46 \pm 38 \%$ vs $32 \pm 22 \%, p=0.271$; Fig. 2 a) nor without $(9 \pm 14 \%$ vs $11 \pm 14 \%, p=0.743) v W F$ abnormalities. Patients with vWF abnormalities in transcatheter population, however, were characterized with lower increase on the third post-interventional day when compared to surgical group $(4 \pm 10 \%$ vs $11 \pm 7 \%, p=0.008$ vs day 1 ; Fig. $2 b$ ). In patients without baseline vWF abnormalities such a disparity was not observed ( $2 \pm 10 \%$ vs $3 \pm 6 \%, p=0.479$ vs day 1 ; Fig. $2 b)$. No differences were found between transcatheter and surgical approach in overall relative increase of vWF:Ac/Ag ratio neither in patients with $(50 \pm 40 \%$ vs $46 \pm 26 \%, \mathrm{p}=1.000$; Fig. 2c) nor without vWF abnormalities $(10 \pm 12 \%$ vs $14 \pm 13 \%, p=0.276$; Fig. 2c). Both TAVI and SAVR had comparable effect on vWF:Ac improvement in patients with and without vWF abnormalities (Supplementary Fig. 2a-c).

Size of bioprosthesis was not found to impact evolution of vWF parameters neither in transcatheter nor surgical patients (Supplementary Material 1).
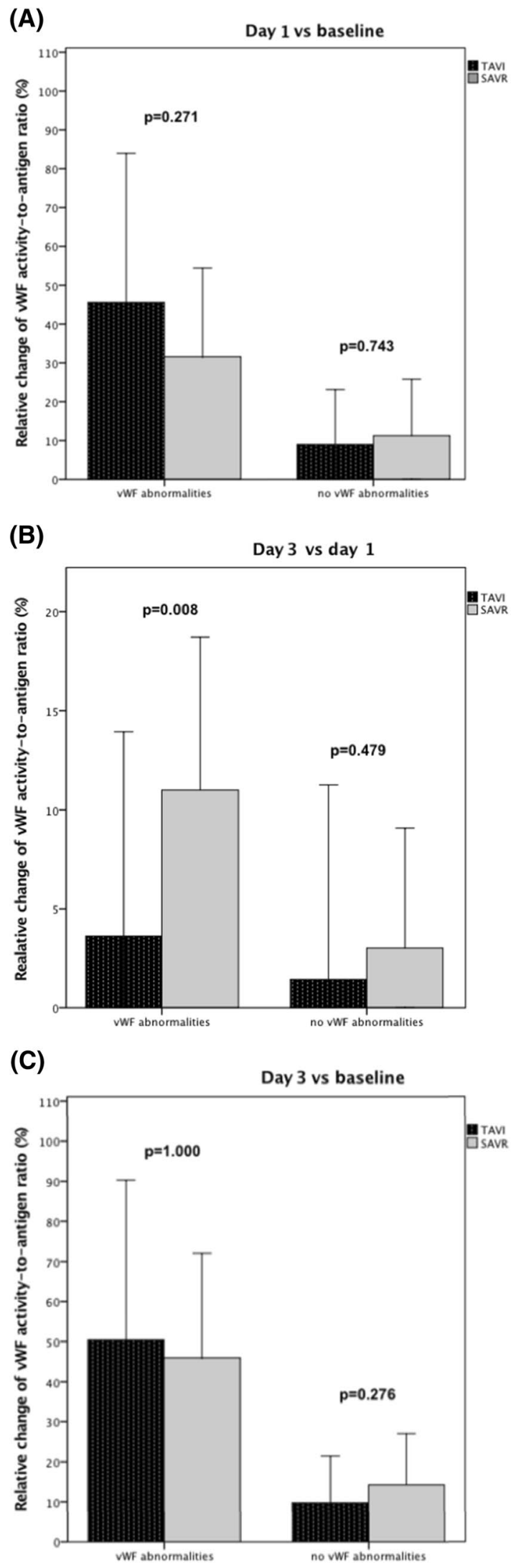

Fig. 2 Relative change of von Willebrand Factor activity-to-antigen ratio: $\mathbf{a}$ on day 1 in comparison to baseline; $\mathbf{b}$ on day 3 in comparison to day 1; c on day 3 in comparison to baseline 
(A) Bleeding complications

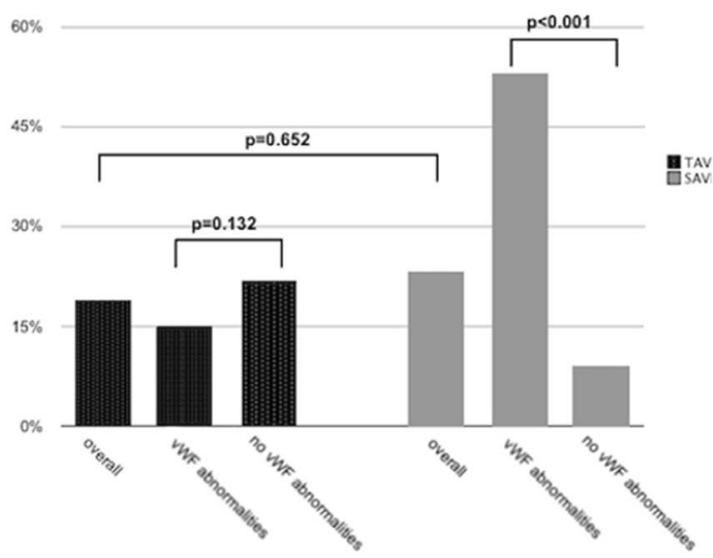

(B)

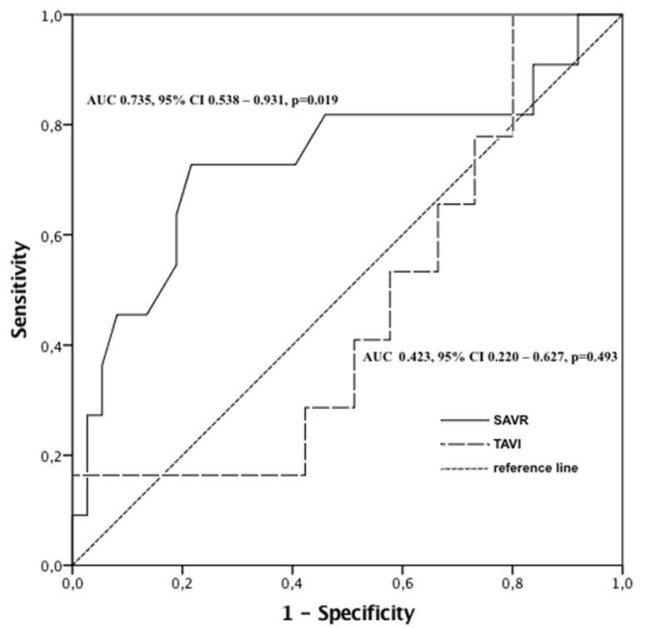

Fig. 3 a Bleeding complication in TAVI and SAVR cohorts. b Receiver operating characteristics (ROC) curves showing sensitivity and specify of von Willebrand Factor activity-to-antigen ratio for prediction of major or life-threatening bleedings in TAVI and SAVR cohorts

Table 2 Causes of periprocedural major or life-threatening bleeding complications stratified by presence of von Willebrand Factor abnormalities in TAVI and SAVR groups

\begin{tabular}{lll}
\hline TAVI & $\begin{array}{l}\text { vWF abnormalities } \\
(\mathrm{n}=20)\end{array}$ & $\begin{array}{l}\text { No vWF abnormalities } \\
(\mathrm{n}=32)\end{array}$ \\
\hline Ilio-femoral injury & $1(5)$ & $2(6)$ \\
Pseudo-aneursym & $0(0)$ & $1(3)$ \\
Access-site bleeding incl. large groin hematoma & $2(10)$ & $4(13)$ \\
\hline SAVR & $(\mathrm{n}=15)$ & $(\mathrm{n}=33)$ \\
\hline Tamponade & $1(6)$ & $1(3)$ \\
Hemothorax & $1(6)$ & $0(0)$ \\
Increased chest output & $4(27)$ & $2(6)$ \\
Chest wall/sternum-related bleeding & $2(13)$ & $0(0)$
\end{tabular}

\section{Bleeding complications and mortality}

Overall, the frequency of bleeding complications was comparable between TAVI and SAVR (19\% vs. $23 \%, \mathrm{p}=0.652$; Fig. 3a). Specific causes of major and life-threatening bleeding complication stratified by von Willebrand abnormalities in both arms are shown in Table 2.

In TAVI cohort, no difference was found between subjects with and without von Willebrand abnormalities in terms of major or life-threatening bleeding $(15 \%$ vs $22 \%, \mathrm{p}=0.132$; Fig. 3a). ROC curve analysis was performed for baseline markers of vWF function to assess their ability to predict major or life-threatening bleeding complications in transcatheter patients, but none showed significant sensitivity and specificity (AUC for vWF:Ac/vWF:Ag ratio was 0.423 , 95\% CI 0.220-0.627, $p=0.493$; Fig. 3b).

In SAVR cohort, patients with von Willebrand abnormalities suffered more frequently from major or life-threatening bleeding (53\% vs $9 \%, \mathrm{p}<0.001$; Fig. 3a) than the remaining. ROC curve analysis of baseline vWF function parameters showed good sensitivity and specificity of the vWF:Ac/ vWF:Ag ratio (AUC 0.735, 95\% CI 0.538-0.931, $\mathrm{p}=0.019$; Fig. $3 b$ ) in predicting MLTB of surgical patients.

Additionally, preprocedural presence of vWF abnormalities did not increase 1-year mortality in neither transcatheter $(10 \%$ vs. $12.5 \%, \mathrm{p}=0.783)$ nor surgical cohort $(6.5 \%$ vs. $3 \%$, $\mathrm{p}=0.559)$.

\section{Discussion}

The main finding of the present study is that that surgical and transcatheter strategies have similar effect on improvement of vWF parameters. To the best of our knowledge, this is the first direct comparison of two approaches. 
Moreover, it was found that vWF abnormalities are predictive of MLTB in surgical patients.

Prevalence of abnormal vWF multimers in AS patients varies considerably across studies-ranging mostly between 20 and 70\% [7, 8]. Differences arise from inconsistent methodology of screening for vWF abnormalities as there are multiple assays available: vWF-ristocetin cofactor activity (vWF:RCo), vWF collagen binding (vWF:CB), closure time of a membrane coated with collagen and adenosine-5'-diphosphate (CT-ADP) with Platelet Function Analyzer (PFA) and finally-considered to be a gold standard-gel electrophoresis [17]. However, significant discrepancies remain even between electrophoretic analyses, probably due to investigation of populations with different AS severity [13]. We used, for the first time, the novel latex-based immunoturbidimetric test to measure vWF activity [15]. The vWF:Ac assay seems to be less affected by high bilirubin, free hemoglobin, lipidemia or genetic polymorphism than vWF:RCo and, therefore, allows for more reliable screening of avWS with loss of HMW multimers-especially in the setting of heart valve disease and mechanical circulatory support $[18,19]$.

We observed similar incidence rates of vWF abnormalities to previous studies utilizing functional vWF assays (vWF:RCo and vWF:CB) in both TAVI and SAVR groups $[10,11]$. Comparable values of preprocedural vWF parameters in transcatheter and surgical cohorts suggest that loss of HMW multimers is rather independent from baseline clinical characteristic (low risk vs high risk). Along with a clear correlation between vWF:Ac and transvalvular gradients, evidence support the idea of $\mathrm{vWF}$ proteolysis induced by shear-stress, legitimizing recently proposed by Van Belle et al. the series circuit model for quantification of heart valve disease severity based on HMW multimers in the peripheral blood [13].

In 1988, Weinstein et al. described correction of vWF abnormalities after SAVR, confirmed further by Vincentelli et al. [7, 20]. In the following years, several other studies showed normalization of vWF defects after SAVR as well as TAVI [7,21-28]. Accordingly, in majority of our patients HMW multimers recovered on the first postprocedural day [7, 21-23]. However, to the best of our knowledge, we report for the first-time comparative data on efficacy of both methods. While Bander et al. showed superior effect of SAVR over balloon aortic valvuloplasty (BAV) on the vWF function in stenotic patients, we found SAVR and TAVI to be equivalent treatment options [10]. Moreover, improvement of vWF parameters was observed in all patients, contrarily to Caspar et al., who evidenced positive effect of procedure mainly in cohort with pre-existing vWF abnormalities [11]. The dynamic of improvement in patients with vWF abnormalities differed, however, between transcatheter and surgical patients. In TAVI group increment of vWF parameters was achieved more rapidly on the first postoperative day, whereas surgical group noted significant improvement also on the third day. Variability in vWF increase indicate potential differences between interventions, but also disparities regarding individual vulnerability to multimer degradation. Both need to be further explored for better risk stratification.

Interestingly, literature concerning the association of vWF abnormalities with perioperative bleeding is lacking the evidence. Dysfunctions of vWF remain often undiagnosed, thus their impact on bleeding complications is probably underestimated [13]. Nevertheless, we found TAVI to be unaffected by vWF abnormalities as opposed to SAVR. Majority of bleeding complications in transcatheter cohorts is access-site related and caused rather by anatomical than hemostatic elements. On the other hand, wound surfaces and drainage sites of SAVR, when subjected to dysfunctional vWF, may trigger increased bleeding. Indeed, none of previous studies on vWF in TAVI found relationship between vWF abnormalities and excessive periprocedural bleeding [29]. Data on SAVR is inconsistent, however factors like type of the sternotomy or duration of cardiopulmonary bypass (CBP) might influence the results.

There are several limitations to our work. Firstly, study is inherent to the limitations of any non-randomized small series. Secondly, electrophoretic analysis of vWF multimers to confirm loss of HMW was not performed. Thirdly, mid- and long-term evaluation of primary disorder parameters were not included. Finally, we were unable to measure impact of postprocedural aortic regurgitation on vWF parameters due to low incidence of moderate and severe cases.

\section{Conclusions}

The present findings indicate that both TAVI and SAVR are effective treatment for $\mathrm{vWF}$ abnormalities, but $\mathrm{vWF}$ abnormalities are predictive of MLTB only in surgical patients.

Funding This work was supported by the grant from Medical University of Warsaw (1WR/NM5/16 to K.G.).

\section{Compliance with ethical standards}

Conflict of interest None.

Open Access This article is distributed under the terms of the Creative Commons Attribution 4.0 International License (http://creativeco mmons.org/licenses/by/4.0/), which permits unrestricted use, distribution, and reproduction in any medium, provided you give appropriate credit to the original author(s) and the source, provide a link to the Creative Commons license, and indicate if changes were made. 


\section{References}

1. Vahidkhah K, Cordasco D, Abbasi M, Ge L, Tseng E, Bagchi P, Azadani AN (2016) Flow-induced damage to blood cells in aortic valve stenosis. Ann Biomed Eng 44(9):2724-2736

2. Di Stasio Enrico, De Cristofaro Raimondo (2010) The effect of shear stress on protein conformation: physical forces operating on biochemical systems: the case of von Willebrand factor. Biophys Chem 153(1):1-8

3. Sakariassen KS, Bolhuis PA, Sixma JJ (1979) Human blood platelet adhesion to artery subendothelium is mediated by factor VIII-Von Willebrand factor bound to the subendothelium. Nature 279(5714):636-638

4. Arya M, Anvari B, Romo GM (2002) Ultralarge multimers of von Willebrand factor form spontaneous high-strength bonds with the platelet glycoprotein Ib-IX complex: studies using optical tweezers. Blood 99(11):3971-3977

5. Tsai HM (2003) Shear stress and von Willebrand factor in health and disease. Semin Thromb Hemost 29(5):479-488

6. Heyde EC (1958) Gastrointestinal bleeding in aortic stenosis. N Eng J Med 259:196

7. Vincentelli A, Susen S, Le Tourneau T, Six I, Fabre O, Juthier F, Bauters A, Decoene C, Goudemand J, Prat A, Jude B (2003) Acquired von Willebrand syndrome in aortic stenosis. N Engl J Med 349(4):343-349

8. Natorska J, Bykowska K, Hlawaty M, Marek G, Sadowski J, Undas A (2011) Increased thrombin generation and platelet activation are associated with deficiency in high molecular weight multimers of von Willebrand factor in patients with moderate-tosevere aortic stenosis. Heart 97(24):2023-2028

9. Tamura T, Horiuchi H, Imai M, Tada T, Shiomi H, Kuroda M, Nishimura S, Takahashi Y, Yoshikawa Y, Tsujimura A, Amano M, Hayama Y, Imamura S, Onishi N, Tamaki Y, Enomoto S, Miyake M, Kondo H, Kaitani K, Izumi C, Kimura T, Nakagawa Y (2015) Unexpectedly high prevalence of acquired von Willebrand syndrome in patients with severe aortic stenosis as evaluated with a novel large multimer index. J Atheroscler Thromb 22:1115-1123

10. Bander J, Elmariah S, Aledort LM, Dlott J, Stelzer P, Halperin JL, Kini AS, Sharma SK (2012) Changes in von Willebrand factorcleaving protease (ADAMTS-13) in patients with aortic stenosis undergoing valve replacement or balloon valvuloplasty. Thromb Haemost 108:86-93

11. Caspar T, Jesel L, Desprez D, Grunebaum L, Samet H, Trinh A, Petit-Eisenmann H, Kindo M, Ohlmann P, Morel O (2015) Effects of transcutaneous aortic valve implantation on aortic valve disease-related hemostatic disorders involving von Willebrand factor. Can J Cardiol 31(6):738-743

12. Pozzi M, Hanss M, Petrosyan A, Vedrinne C, Green L, Dementhon J, Pizzighini S, Rioufol G, Finet G, Obadia J (2014) Resolution of acquired von Willebrand syndrome after transcatheter aortic valve implantation through a left transcarotid approach. Int J Cardiol 176(3):1350-1351

13. Van Belle E, Vincent F, Rauch A (2019) von Willebrand factor and management of heart valve disease: JACC review topic of the week. J Am Coll Cardiol 73(9):1078-1088

14. Baumgartner H, Falk V, Bax JJ, De Bonis M, Hamm C, Holm PJ, Iung B, Lancellotti P, Lansac E, Muñoz DR, Rosenhek R, Sjögren J, Mas PT, Vahanian A, Walther T, Wendler O, Windecker S, Zamorano JL (2017) 2017 ESC/EACTS guidelines for the management of valvular heart disease. Eur Heart J 38(36):2739-2791

15. Geisen U, Zieger B, Nakamura L, Weis A, Heinz J, Michiels JJ, Heilmann C (2014) Comparison of Von Willebrand factor (VWF) activity VWF: Ac with VWF ristocetin cofactor activity VWF:RCo. Thromb Res 134(2):246-250
16. Kappetein AP, Head SJ, Généreux P et al (2012) Updated standardized endpoint definitions for transcatheter aortic valve implantation: the Valve Academic Research Consortium-2 consensus document (VARC-2). J Am Coll Cardiol 60(15):1438-1454

17. Warkentin TE, Moore JC, Anand SS, Lonn EM, Morgan DG (2003) Gastrointestinal bleeding, angiodysplasia, cardiovascular disease, and acquired von Willebrand syndrome. Transfus Med Rev 17:272-286

18. Lawrie AS, Stufano F, Canciani MT, Mackie IJ, Machin SJ, Peyvandi $F$ (2013) A comparative evaluation of a new automated assay for von Willebrand factor activity. Haemophilia 19:338-342

19. Flood VH, Gill JC, Morateck PA, Christopherson PA, Friedman KD, Haberichter SL, Branchford BR, Hoffmann RG, Abshire TC, Di Paola JA, Hoots WK, Leissinger C, Lusher JM, Ragni MV, Shapiro AD, Montgomery RR (2010) Common VWF exon 28 polymorphisms in African Americans affecting the VWF activity assay by ristocetin cofactor. Blood 116:280-286

20. Weinstein M, Ware JA, Troll J, Salzman E (1988) Changes in von Willebrand factor during cardiac surgery: effect of desmopressin acetate. Blood 71:1648-1655

21. Van Belle E, Rauch A, Vincentelli A et al (2015) Von Willebrand factor as a biological sensor of blood flow to monitor percutaneous aortic valve interventions. Circ Res 116:1193-1201

22. Marggraf O, Schneppenheim S, Daubmann A, Budde U, Seiffert M, Reichenspurner H, Treede H, Blankenberg S, Diemert P (2014) Correction of acquired von Willebrand syndrome by transcatheter aortic valve implantation. J Invasive Cardiol 26:654-658

23. Casonato A, Sponga S, Pontara E, Cattini MG, Basso C, Thiene G, Cella G, Daidone V, Gerosa G, Pagnan A (2011) von Willebrand factor abnormalities in aortic valve stenosis: pathophysiology and impact on bleeding. Thromb Haemost 106:58-66

24. Pawlitschek F, Keyl C, Zieger B, Budde U, Beyersdorf F, Neumann FJ, Stratz C, Nührenberg TG, Trenk D (2018) Alteration of von Willebrand factor after transcatheter aortic valve replacement in the absence of paravalvular regurgitation. Thromb Haemost 118:103-111

25. Pareti FI, Lattuada A, Bressi C, Zanobini M, Sala A, Steffan A, Ruggeri ZM (2000) Proteolysis of von Willebrand factor and shear stress-induced platelet aggregation in patients with aortic valve stenosis. Circulation 102:1290-1295

26. Solomon C, Budde U, Schneppenheim S, Czaja E, Hagl C, Schoechl H, von Depka M, Rahe-Meyer N (2011) Acquired type 2A von Willebrand syndrome caused by aortic valve disease corrects during valve surgery. Br J Anaesth 106:494-500

27. Bolliger D, Dell-Kuster S, Seeberger MD, Tanaka KA, Gregor M, Zenklusen U, Tsakiris DA, Filipovic M (2012) Impact of loss of high-molecular-weight von Willebrand factor multimers on blood loss after aortic valve replacement. Br J Anaesth 108:754-762

28. Yamashita K, Yagi H, Hayakawa M, Abe T, Hayata Y, Yamaguchi N, Sugimoto M, Fujimura Y, Matsumoto M, Taniguchi S (2016) Rapid restoration of thrombus formation and high-molecularweight von Willebrand factor multimers in patients with severe aortic stenosis after valve replacement. J Atheroscler Thromb 23:1150-1158

29. Spangenberg T, Budde U, Schewel D, Frerker C, Thielsen T, Kuck KH, Schäfer U (2015) Treatment of acquired von Willebrand syndrome in aortic stenosis with transcatheter aortic valve replacement. JACC Cardiovasc Interv 8(5):692-700

Publisher's Note Springer Nature remains neutral with regard to jurisdictional claims in published maps and institutional affiliations. 